http://dx.doi.org/10.4314/ajtcam.v10i3.29

\title{
STUDY ON ANTI-TUMOR EFFECT OF TOTAL GLYCOSIDES FROM RADIX PAEONIAE RUBRA IN S180 TUMOR-BEARING MICE
}

\author{
Wanpeng $\mathrm{Xu}^{1 \dagger}$, Wei Zhong ${ }^{2 \dagger}$, Jinlan $\mathrm{Liu}^{2}$, Hong Liu ${ }^{3}$, Bing $\mathrm{Zhu}^{2 *}$
}

${ }^{1}$ Department of Colon\&Anorectal Surgery, Affiliated Hospital of Weifang Medical University, Weifang, 261031, China., ${ }^{2}$ Department of Joint Surgery, Affiliated Hospital of Weifang Medical University, Weifang, 261031, China, ${ }^{3}$ Department of Nursing Pept, Affiliated Hospital of Weifang Medical University, Weifang, 261031, China. $\uparrow$ Authors contributed equally to this work.

*Email: xuwanpeng123@yeah.net

\begin{abstract}
The objective of the paper was to study the anti-tumor effect of total glycosides from Radix paeoniae rubra in S180 tumor-bearing mice, and to preliminarily explore its mechanism of action. Mice were made into S180 solid tumor model, grouped and administered with the extracts; tumor inhibition rate was measured by harvesting the tumors, and serum IL-2 and IL-4 levels were measured by taking blood samples. Total glycosides of Radix paeoniae rubra significantly inhibited the growth of tumor cells in tumor-bearing organisms, enhanced the cytotoxic activity of NK cells, and increased the serum IL-2 and IL-4 levels. Total glycosides of Radix paeoniae rubra have some anti-tumor effect in vivo, which might have been accomplished through the regulation of the immune system.
\end{abstract}

Keywords: total glycosides of Radix Paeoniae Rubra, S180 sarcoma, IL-2, IL-4

\section{Introduction}

Radix Paeoniae Rubra (Chishao) is the dried root of Paeonia lactiflora Pall. or Paeonia veitchii Lynch., it is bitter in taste, slightly cold, and enters the liver meridian, which has the heat-clearing, blood-cooling, stasis-dissipating and analgesic effects (Chinese Pharmacopoeia Commission, 2010). Radix Paeoniae Rubra is mainly grown in provinces such as Inner Mongolia, Hebei, Liaoning, Heilongjiang and Jilin of China(Jiangsu New Medical College,1993). Modern pharmacological studies have shown that Radix paeoniae rubra has the hepatoprotective(Li et al.,2003), anti-atherosclerotic(Zhu et al.,2003), antithrombotic(Xu et al.,2000), anti-platelet aggregation(Xu et al.,2003), hypoglycemic(Zhang et al.,1990) and anti-tumor(Yu et al.,2005; Xu et al.,2007\&2008) effects. Chemical studies have found that Radix paeoniae rubra contains monoterpene glycosides (Kaneda et al.,1972; Nobutoshi et al.,1996), tannins(Makoto et al.,1983), triterpenoids (Kohei et al.,1997) and other constituents, of which the main constituent is total glycosides of Chishao (TGC). TGC is an effective component extracted from Radix paeoniae rubra, which has a complex chemical composition containing Chishaojiasu, Chishaoyisu, benzoic acid, glycosides, etc. In this paper, S180 solid tumor animal model was used to study the anti-tumor effect of TGC.

\section{Experimental Materials}

Drugs and reagents

Radix Paeoniae Rubra (Baidu Medicine Co., Ltd.); RPMI 1640 medium (GIBCOBRL); MTT, ConA (Sigma); CTX (Jiangsu Hengrui Medicine Co., Ltd.); IL-2, IL-4 kit (Beijing Furui Bioengineering Co., Ltd.) 
http://dx.doi.org/10.4314/ajtcam.v10i3.29

\section{Main instruments}

AE31 inverted phase contrast microscope (Motic); SW-CJ-IF clean bench (Suzhou Purification Equipment Factory); low-temperature refrigerated centrifuge (Eppendorf, Germany); electronic balance (Beijing Sartorius Instrument System Co., Ltd.); blood counting chamber (Shanghai Qiujing Biochemical Instrument Factory).

\section{Experimental animals}

Kunming mice, half male and half female, weighing 18 22 g, purchased from the Laboratory Animal Center of Weifang Medical University. All experimental procedures were approved by the Animal Research Ethics Committee of Weifang Medical University, Weifang, China (wf12/01/25).

\section{S180 tumor lines}

Purchased from the KeyGEN Biotech Co., Ltd.

\section{Preparation of TGC}

Dried Radix paeoniae rubra was crushed with a mortar and pestle, placed in a round bottom flask, added with a 10 -fold volume of ethanol, and heat extracted three times ( $1.5 \mathrm{~h}$ each time), then filtered, the filtrates were combined, and solvent was removed until no alcohol smell was present. The concentrated solution was placed in a separating funnel, and extracted by adding petroleum ether. The petroleum ether layer was separated, and the remaining layer was extracted several times by adding n-butanol, then the n-butanol solutions were combined. Solvent was removed, and the concentrated solution was passed through a silica gel column chromatography, and eluted with ethyl acetate solvent, after solvent removal, total glycosides of Radix Paeoniae Rubra was obtained, which was stored at $4^{\circ} \mathrm{C}$ for later use.

\section{Establishment of animal model (Li et al.,2006)}

7 days after inoculation of S180, mice whose abdominal circumferences increased to the maximum were sacrificed by cervical dislocation; after abdomen disinfection, abdominal cavities were cut open, and ascites were extracted with $1 \mathrm{~mL}$ sterile syringes; the ascites were diluted with PBS, centrifuged at $1000 \mathrm{rpm} / \mathrm{min}$ for $10 \mathrm{~min}$, then the supernatant was discarded. Viable cells were counted using trypan blue staining method, and tumor cell number was adjusted to $1 \times 10^{6}$ cells $/ \mathrm{mL}$. 40 mice were selected and their right armpit skin was disinfected, tumor cell suspension was $0.2 \mathrm{~mL}$ was subcutaneously injected into the right forelimb armpit of each mouse using $1 \mathrm{~mL}$ sterile syringes to create solid tumor model.

\section{Grouping and treatment}

$24 \mathrm{~h}$ after inoculation, the 40 mice were randomly divided into model group, CTX group, TGC group, and combined treatment group (TGC plus CTX), with each group containing 10 mice. Another 10 mice which were not inoculated with tumor cells served as the normal control group. All mice were given enough water and food, and mice in each group were weighed and their body weights were recorded. CTX group was intraperitoneally injected with $100 \mathrm{mg} / \mathrm{kg}$ CTX on the $3 \mathrm{rd}$ day; dosage in TGC group was $120 \mathrm{mg} / \mathrm{kg} / \mathrm{d}$; combined treatment group was intragastrically administered $120 \mathrm{mg} / \mathrm{kg} / \mathrm{d} \mathrm{TGC}$, and intraperitoneally injected with $100 \mathrm{mg} / \mathrm{kg}$ CTX on the 3rd day. Mental states, physical activities and feeding status of mice were observed daily for seven consecutive days. 
http://dx.doi.org/10.4314/ajtcam.v10i3.29

\section{Determination of tumor inhibition rate}

On the 8th day after administration, after weighing, eyeballs were enucleated and blood was sampled from the eyeballs, the mice were sacrificed, tumors were harvested and weighed, and tumor inhibition rate was calculated according to the following formula.

Tumor inhibition rate $=$ (average tumor weight of control group - average tumor weight of experimental group) / average tumor weight of control group $\times 100 \%$

\section{Direct in-vitro tumor inhibitory effect of TGC}

MTT assay: Ascites rich in S180 cells were taken, washed three times with Hank's solution, placed in RPMI1640 complete medium and cultured, cells were passaged once every three days, and cells after three passages were used in the experiment. Cells with a density of $5 \times 10^{6}$ cells $/ \mathrm{mL}$ were added to each well of 24 -well plates, at the same time, different concentrations of TGC solutions, with final concentrations of $1.0 \mathrm{mg} / \mathrm{ml}, 0.8 \mathrm{mg} / \mathrm{ml}, 0.6 \mathrm{mg} / \mathrm{ml}, 0.4 \mathrm{mg} / \mathrm{ml}, 0.2 \mathrm{mg} / \mathrm{ml}$ and 0 $\mathrm{mg} / \mathrm{ml}$ respectively, were added as well. Total fluid volume of each well was $200 \mathrm{ul}$, four parallel wells were set up, plates were incubated in a $37{ }^{\circ} \mathrm{C}, 5 \% \mathrm{CO}_{2}$ incubator for $24 \mathrm{~h}$, then $100 \mathrm{ul}$ of supernatant was discarded from each well, $15 \mathrm{ul}$ of MTT was added, and the cells were incubated for another $4 \mathrm{~h}$, after that, $100 \mathrm{ul}$ of pure DMSO solution was added to each well, and allowed to stand for $20 \mathrm{~min}$, OD value was measured at $570 \mathrm{~nm}$ with a microplate reader.

\section{Effect of TGC on NK cell activity in mice}

Preparation of mouse splenic lymphocyte suspension was carried out according to the method of Fatima et al. (2006). Mice in each group were sacrificed by cervical dislocation, and spleens were harvested under sterile conditions, cut into small pieces, disaggregated into a single cell suspension using Medimachine, centrifuged at $1000 \mathrm{r} / \mathrm{min}$ for $5 \mathrm{~min}$, then the supernatant was discarded. After washing in PBS twice, the cells were prepared into $5 \times 10^{6}$ cells $/ \mathrm{mL}$ with RPMI-1640 medium containing 10\% fetal bovine serum, and blown uniformly for later use.

Serially passaged YAC- 1 cells with a concentration of $5 \times 10^{6}$ cells $/ \mathrm{mL}$ served as target cells, the effector and target cells were incubated in a $37{ }^{\circ} \mathrm{C}, 5 \% \mathrm{CO} 2$ incubator for $4 \mathrm{~h}$, then added with $10 \mu \mathrm{L}$ of MTT solution $(5 \mathrm{mg} / \mathrm{mL})$, and incubated for another $4 \mathrm{~h}$, then centrifuged for $10 \mathrm{~min}$ (3000 r/min), supernatant was discarded, and each well was added with $100 \mu \mathrm{L}$ of DMSO, after fully shaken, OD value was measured at $570 \mathrm{~nm}$.

\section{Measurement of IL-2 and IL-4 levels in mouse serum}

Mice eyeballs were enucleated and blood was sampled from the eyeballs, the blood samples were placed in a centrifuge tube, centrifuged at $3000 \mathrm{rpm}$ for $5 \mathrm{~min}$ to obtain serum, and measurement was performed according to kit instructions and by ELISA method.

\section{Statistical methods}

Experimental data were analyzed using the SPSS 13.0 software, comparisons between two groups were performed using t-test, and pairwise comparisons among groups were performed using one-way ANOVA. 
http://dx.doi.org/10.4314/ajtcam.v10i3.29

\section{Results}

Effect of TGC on growth of S180 sarcoma in mice in vivo

The results of the effect of TGC on tumor weight and tumor inhibition rate are as shown in Table 1. Daily intragastric administration of $120 \mathrm{mg} / \mathrm{kg}$ TGC significantly inhibited the growth of tumor cells, where the tumor inhibition rate was $40.58 \%$. The effect is better when TGC is used in combination with CTX, where the tumor inhibition rate was $69.57 \%$, which is not significantly different $(\mathrm{P}>0.05)$ than that treated with $\mathrm{CTX}$ alone. Tumor inhibition rates in various groups, when compared with the model group, all showed significant differences $(\mathrm{P}<0.05$ or $\mathrm{P}<0.01)$, suggesting that TGC has a significant inhibitory effect on solid tumors in S180 tumor-bearing mice.

Table 1: Effect of TGC on growth of S180 sarcoma in mice in vivo $(\bar{X} \pm \mathrm{S})$

\begin{tabular}{llll}
\hline Group & Number of animals & Tumor weight $(\mathrm{g})$ & $\begin{array}{l}\text { Tumor inhibition rate } \\
(\%)\end{array}$ \\
\hline Model group & 10 & $2.07 \pm 0.45$ & - \\
CTX group & 10 & $0.71 \pm 0.31^{* *}$ & 65.70 \\
TGC group & 10 & $1.23 \pm 0.38^{*}$ & 40.58 \\
Combined treatment & 10 & $0.63 \pm 0.44^{* *}$ & 69.57 \\
group & & & \\
\hline
\end{tabular}

Comparison with the model group, $* \mathrm{P}<0.05 ; * * \mathrm{P}<0.01$

Results for the direct in-vitro tumor inhibitory effect of TGC

Cytotoxic effect of TGC on S180 was observed by MTT assay, the results showed that the TGC had no direct inhibitory effect on S180 in vitro.

\section{Results for the effect of TGC on NK cell activity in mice}

The results for the effect of TGC on NK cell activity in mice are as shown in Table 2. NK cell cytotoxicity in model group, when compared with the normal group, was significantly reduced $(\mathrm{p}<0.05)$; after treatment with TGC, NK cell cytotoxicity improved, which was not significantly different compared with the normal group; CTX can reduce the cytotoxicity of NK cells, no significant difference in cytotoxicity was seen when compared with the model group, and a significant decrease of cytotoxicity was seen when compared with the normal group $(p<0.01)$. The combined treatment group completely antagonized the immunosuppression caused by CTX, and enhanced the cytotoxic activity of NK cells, which was not significantly different compared with the normal group.

Table 2: Effect of TGC on NK cell activity in mice $(n=10, \bar{X} \pm S)$

\begin{tabular}{|c|c|}
\hline Group & NK cytotoxicity/\% \\
\hline Normal control group & $39.34 \pm 2.32$ \\
\hline Model group & $33.36 \pm 1.46^{*}$ \\
\hline CTX group & $31.45 \pm 1.58 * *$ \\
\hline TGC group & $43.45 \pm 3.12 \lesssim 认$ \\
\hline Combined treatment group & $38.43 \pm 1.87$ 饮 \\
\hline
\end{tabular}

Comparison with the normal control group, ${ }^{*} \mathrm{P}<0.05 ; * * \mathrm{P}<0.01$

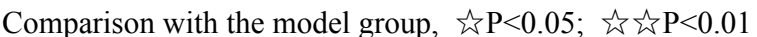




\section{Effect of TGC on serum IL-2 and IL-4 levels in tumor-bearing mice}

The effect of TGC on serum IL-2 and IL-4 levels in tumor-bearing mice is as shown in Table 3, compared with the normal control group, serum IL-2 level decreased significantly $(\mathrm{P}<0.05)$ in mice of model group. After treatment with TGC, IL-2 level significantly increased, showing a significant difference $(\mathrm{P}<0.01)$ compared with the model group, and no significant difference compared with the normal group. IL-2 level in CTX group was significantly lower $(\mathrm{P}<0.01)$ than that of the normal control group, which was also significantly different $(\mathrm{P}<0.05)$ compared with the tumor-bearing control group, indicating that the CTX has a relatively strong inhibitory effect; when TGC and CTX were used in combination, IL-2 level increased, indicating that the TGC can significantly improve the inhibitory effect of CTX.

IL-4 level decreased significantly $(\mathrm{P}<0.05)$ in model group compared with the normal control group; after treatment with TGC, IL-4 level was significantly elevated $(\mathrm{P}<0.01)$ compared with the model group; no significant difference was seen in IL-4 levels between CTX group and model group; when TGC and CTX were used in combination, inhibitory effect of CTX was improved significantly.

Table 3: Effect of TGC on serum IL-2 and IL-4 levels in tumor-bearing mice

\begin{tabular}{|c|c|c|c|}
\hline Group & Number of animals & IL-2（pg/mL $)$ & IL-4（pg/mL $)$ \\
\hline Normal control group & 10 & $118.432 \pm 5.523$ & $161.356 \pm 29.327$ \\
\hline Model group & 10 & $102.563 \pm 4.554^{*}$ & $109.873 \pm 36.971^{*}$ \\
\hline CTX group & 10 & $94.216 \pm 11.358 * *$ 次 & $113.746 \pm 42.198 * *$ \\
\hline TGC group & 10 & 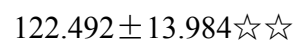 & 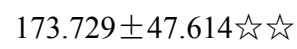 \\
\hline $\begin{array}{l}\text { Combined } \\
\text { group }\end{array}$ & 10 & $114.523 \pm 10.573$ 约 & 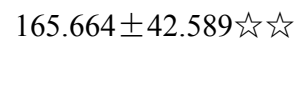 \\
\hline
\end{tabular}

Comparison with the normal control group, $* \mathrm{P}<0.05 ; * * \mathrm{P}<0.01$

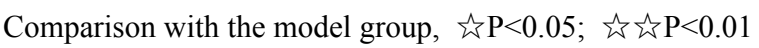

\section{Discussion}

Radix Paeoniae Rubra is an important blood circulation-invigorating and stasis-eliminating traditional Chinese medicine, which is often used in combination with other drugs for the treatment of blood stasis syndromes and neoplastic diseases, however, the immunological mechanism of its anti-tumor effect and its active constituents are yet to be clarified. It can be presumed based on the research results that the TGC may be one of the effective anticancer constituents of Radix Paeoniae Rubra. No direct cytotoxic effect of TGC on S180 sarcoma cells was observed in the in-vitro experiment, thus it can be inferred that the anti-tumor effect of TGC is accomplished through the regulation of the immune system. Core components constituting the immune system are lymphocytes (Soumya and Melanie,2010), which can be divided into T cells, B cells and NK cells according to their functions. NK cell (natural killer cell) is a type of cell existing in the body which has natural killing ability. Although its cytotoxic activity is weaker than T cells and B cells, but the effect occurs quickly, which is one of the body's important non-specific defense functions. $\mathrm{CD}_{4}{ }^{+} \mathrm{T}$ cells are divided into Thl cells and $\mathrm{Th} 2$ cells since they secrete different cytokines, Thl cells mainly secrete IL-2, participate in the cytotoxic T lymphocyte (CTL)-mediated cellular immunity, and play a role in the anti-tumor and anti-intracellular infection; Th2 cells mainly secrete IL-4, its function is to stimulate B cell proliferation, promote antibody production, participate in humoral immunity and to play a major role in the anti-extracellular infection and immune response caused by allergens. The body's anti-tumor immune response involves a variety of immune components, and it is generally believed that the cellular immunity plays an important role in the tumor 
http://dx.doi.org/10.4314/ajtcam.v10i3.29

inhibition. Although CTX has a strong tumor inhibitory effect, it suppresses immune function and lowers immunity at the same time, which is not conducive to the control of tumor metastasis and progression. When CTX is used in combination with TGC, various indices are all improved to near normal levels, indicating that the TGC can reverse the T cell immune suppression and immune dysfunction induced by tumor antigens and CTX, which has a relatively strong immunoregulatory effect.

\section{References}

1. Chinese Pharmacopoeia Commission. (2010). Pharmacopoeia of the People's Republic of China, Volume I, 2010 edition. Beijing: China Medical Science Press, 147-148.

2. Fatima R.D., JoseAlexandre M.B., Maristela T,et al. (2006). Discrimination between NK and LAK cytotoxic activities of murine spleen cell by MTT assay: differential inhibition by PGE2 and DETA.J Immunol Methods, 241: 121-129.

3. Jiangsu New Medical College. (1993). Dictionary of Chinese Materia Medica. Shanghai: Shanghai Scientific \& Technical Publishers, 1093.

4. Kaneda M., Iitaka Y., Shibata S. (1972). Chemical studies on the oriental plant drugs. X X X III. The absolute structures of paeoniflorin, albiflorin, oxypaeoniflorin and benzoylpaeoniflorin isolated from Chinese paeony root. Tetrahedron, 28(10): 4309-4317.

5. Kohei K., Yobe G., Yasuhisa S., et al. (1997). Triterpenoids and floavonoids fromPaeonia lactiflor. Phytochemistry, 44(1): 141-144.

6. Li Y.K., Jin R.M., Wang Q.M. (2006). Experimental Methodology of TCM Pharmacology (2nd Edition). Shanghai Scientific \& Technical Publishers, 777-779.

7. Li Y.C., Sun Y.F., Feng Z.J., et al.(2003). Experimental Study on Antagonizing Liver Fibrosis of Radix Paeoniae Rubra. Chinese Journal of Integrated Traditional and Western Medicine, 23 (10): 767-768.

8. Soumya B., Melanie M. (2010). Scale invariance of immune system response rates and times: perspectives on immune system architecture and implications for artificial immune systems. Swarm Intelligence, 23(4):301-318.

9. Xu H.M., Liu Q.Y., Dai M., et al. (2000). The Antithrombotic Effect of Total Glucosides of Chishao. 19 (1): 46-47.

10. Xu H.M., Liu Q.Y., Dai M., et al. (2003). Effect of total glucosides of radix paeoniae rubra on platelet function in rats. Journal of Hefei University of Technology (Natural Science), 26 (1): 141-144.

11. Xu H.Y., Chen Z.W., Wang J.F., et al. (2007). Effect of total glucosides from Radix Paeoniae Rubra on apoptosis of hepatoma cells in mice. Chinese Traditional and Herbal Drugs, 37(9): 1364-1367.

12. Xu H.Y., Chen Z.W., Niu J.Z., et al. (2008). K562 cell apoptosis induced by total glucosides of Radix Paeoniae Rubra and its effect on mitochondrial membrane potential and $\mathrm{Ca} 2+$. Journal of Clinical Rehabilitative Tissue Engineering Research, 12 (16): 3123-3126.

13. Yu X.H., Yu Y., Hua D. (2005). Study on the anti-tumor immune mechanism of total glycosides of Chishao in tumor-bearing mice. Journal of Jiangxi University of Traditional Chinese Medicine, 17 (1): 61-62.

14. Makoto N., Takahashi Y., Nonaka G.I., et al. (1983). Tannins and related compounds . Isolation and characterization of galloylglucoses from Paeoniae radix and their effect on urea-nitrogen concentration in rat serum. Chem Pharm Bull, 31(8): 2593-2600.

15. Nobutoshi M., Massami S., Hirpmi S., et al. (1996). New bioactivemonoterpene glycosides from Paeoniae radix.Chem Pharm Bull, 44(6): 1279-1281.

16. Zhang Y.Z., Yan X.F. (1990). Effect of Radix Paeoniae Rubra and nifedipine on plasma TXB2 and 6-keto-PGF1 $\alpha 2$ in chronic hyperlipidemic rabbits. Chinese Journal of Integrated Traditional and Western Medicine, 10 (11): 669-671.

17. Zhu H.M., Zhu B.D. (2003). Vascular Remodeling After Carotid Balloon Injury by Paeoniae Rubra in Rabbits. Journal of Chinese Microcirculation, 7 (3): 154-156. 